\title{
A suggested Proposal for Applying the Electronic Administration in the Secondary Industrial Technical Schools: (A field Study at Aswan Governorate)
}

\section{Zeinab Mohamed Sedeek Hassan, Badry Ahmed Abuelhassan and . HananAbdelsatar Mahmoud}

Faculty of Education, South Valley University

\begin{abstract}
The study aims to know the requirements of applying the electronic administration in the secondary industrial schools at Aswan governorate, and the study used the descriptive analytical, depend on questionnaire as a tool to it, and applied on. The study aimed to identify the requirements of the application of electronic administration in industrial secondary schools. The study used the descriptive method. The study relied on the questionnaire as a tool that was applied to a sample of teachers, administrators, technicians and engineers in Aswan schools. And administrative, and 44 technicians and engineers, Including 70 teachers and administrators, 44 technicians and engineers, then The study presented a suggested proposal for applying of electronic administration in industrial technical secondary schools. The study reached a number of results, the most important of which are: Industrial technical education curricula do not keep up the requirements of the labor market, it is not related to the practical study, and the objectives are traditional, in addition to the society's low opinion.Admission Policy do not considers tendencies and the trends of students but accept them according to the low groups in the preparatory certificate - The school is not keen on the availability of specialists in operation and maintenance of electronic devices ،

Lack of financial support necessary for purchase and maintenance of equipment and training personnel ، Lack of interest in the school to provide an electronic network of communication between teachers and administrators and between the school and management on the one hand and between the directorate of education on the other hand, and lack of programs that meet the needs of the school ' Lack of interest in the school to amend the organizational structure commensurate with the application of electronic management, and not keen to simplify procedures when switching to electronic management.
\end{abstract}

Keywords: Electronic Administration; the Secondary Technical Schools

Citation : Hassan et.al., prepare a program in the Islamic culture based on self-regulated learning for Developing some religious concepts and tourism attitudes of Faculty of Tourism and Hotels Students. SVU-Journal of abstract 2019, Vol.1: pp3 (retrieved from the Journal of Educational Sciences; 2018, No.34; pp53).

Copyright: Publisher South Valley University. which permits unrestricted use, distribution and reproduction in any medium provided the original author and source are created. 